\title{
ENSINO COM PESQUISA: CONTRIBUIÇÕES PARA A CIENTIFICIDADE NA FORMAÇÃO EM SECRETARIADO EXECUTIVO
}

\section{EDUCATION WITH RESEARCH: CONTRIBUTIONS TO THE SCIENTISM IN THE EXECUTIVE SECRETARIAT DEGREE}

\author{
Conceição de Maria Pinheiro Barros \\ Doutoranda em Educação pela Universidade Federal do Ceará - UFC. \\ Professora Assistente da Universidade Federal do Ceará. \\ E-mail: conceicaompb@yahoo.com.br (Brasil)
}

\section{Joelma Soares da Silva}

Doutorando em Administração na Universidade Estadual do Ceará - UECE.

Professora Assistente e Coordenadora do Curso de Secretariado Executivo da Universidade Federal do Ceará.

E-mail: joelma.soares@ufc.br (Brasil)

\section{Ana Paula da Cruz Holanda Barros}

Mestrado em Administração de Empresas pela Universidade Federal do Ceará - UFC.

Secretária Executiva da Universidade Federal do Ceará

E-mail: apholanda@hotmail.com (Brasil) 


\section{ENSINO COM PESQUISA: CONTRIBUIÇÕES PARA A CIENTIFICIDADE NA FORMAÇÃO EM SECRETARIADO EXECUTIVO}

\section{RESUMO}

O ensino com pesquisa pode ser considerado como um método capaz de contribuir para a docência universitária a qual deve incluir em sua prática a pesquisa científica. Insere-se nesse contexto a formação em Secretariado Executivo, cujo desenvolvimento de pesquisa científica na prática docente pode estimular os discentes ao interesse pela construção de conhecimentos na área. Este trabalho tem por objetivo investigar as contribuições dessa abordagem para a cientificidade secretarial. Para tanto, foi desenvolvida uma pesquisa qualitativa por meio das técnicas de pesquisa observação participante e narrativa escrita. A partir da observação participante, registrada em diário de campo, apresenta-se o relato de experiência docente por meio da descrição do desenvolvimento e dos resultados alcançados com a utilização do ensino com pesquisa científica desenvolvido nas disciplinas Dinâmica Gerencial, Comportamento Organizacional e Estágio Supervisionado, no curso de Secretariado Executivo da Universidade Federal do Ceará, no período de 2012 a 2014, com a participação de 73 alunos, dois docentes e uma servidora técnico-administrativa. As narrativas escritas foram realizadas por 19 estudantes que desenvolveram o Estágio Supervisionado, em 2014. A interpretação das informações foi realizada numa perspectiva hermenêutica fundamentada na compreensão interpretativa fenomenológica. Inferiu-se que as contribuições do ensino com pesquisa para a cientificidade secretarial ocorrem principalmente, pelo fato de formar um novo perfil acadêmico e profissional por meio de uma cultura científica no curso; insere o educando no processo investigativo durante a realização das disciplinas estudadas ao longo de sua trajetória universitária. Tal cultura possibilita a busca por respostas às inquietações que surgem na profissão e colabora para reforçar a identidade do Secretariado como área de conhecimento em construção.

Palavras-chave: educação superior; ensino com pesquisa; secretariado executivo. 


\title{
EDUCATION WITH RESEARCH: CONTRIBUTIONS TO THE SCIENTISM IN THE EXECUTIVE SECRETARIAT DEGREE
}

\begin{abstract}
The education with research can be considered as a method capable of contributing to the academic teaching that must include in its own practice the scientific research. It is inserted in this context the academic background in Executive Secretariat, of which scientific research development in the teaching practice can stimulate the professors through the interest about the construction of knowledge in the field. This work aims to investigate the contributions of this approach to the secretarial scientism. In order to do so, it has been developed a qualitative research through research techniques, participative observation and written narrative. From the participative observation, recorded on field diary, it is presented the teaching experience report through the description of the development and the results obtained with the application of the teaching with scientific research developed in the subjects Managerial Dynamic, Organizational Behavior and Supervised Traineeship, in the course of Executive Secretariat of the Federal University of Ceará, during the period from 2012 to 2014, with the participation of 73 students, two professors and one technicaladministrative servant. Students who attended the Supervised Traineeship, in 2014, performed the written narratives. The interpretation of the data was performed in a hermeneutic perspective in the phenomenological interpretative comprehension. It has been inferred that the contributions of teaching with research to the secretarial scientism occur mostly, by the fact that it creates a new academical and professional profile through a scientific culture in the course; it inserts the academic in the investigative process during the accomplishment of the subjects studied throughout his/her academic trajectory. Such culture allows the search for answers to the worries that emerge in the profession and contribute to strengthen the identity of the secretariat as field of knowledge in construction.
\end{abstract}

Keywords: higher education; teaching with research; executive secretariat. 


\section{Introdução}

A universidade tem como função a integração entre ensino, pesquisa e extensão; entretanto tal dever nem sempre é praticado em todas as instituições de ensino, motivo pelo qual se torna um desafio a ser superado. A concretização dessa tríade é o que possibilita a oferta de respostas às demandas sociais. Nesse contexto, o professor tem um papel fundamental e deve desenvolver essas atividades de forma interligada. Considera-se a pesquisa como um dos principais meios de difusão dos conhecimentos gerados no âmbito acadêmico para a comunidade, desde que haja um diálogo com o ensino e a extensão. O ensino com pesquisa pode ser compreendido como uma estratégia capaz de contribuir para esse desafio na docência universitária. No âmbito acadêmico em Secretariado, vive-se um momento de construção de identidade no mundo científico por meio da ampliação de estudos e pesquisas que, embora ainda em fase de elaboração, têm contribuído para a consolidação da área. Discussões acerca da sua cientificidade (eg.: Hoeller, 2006; Sabino \& Marchelli, 2009; Nonato Júnior, 2009; Nascimento, 2012; Bíscoli \& Billert, 2013) têm sido fundamentais para esse processo, entretanto, ainda há muito a ser estudado a esse respeito.

Ao considerar-se que "a pesquisa é um dos requisitos metodológicos indispensáveis para qualquer profissional em uma sociedade global” (Lampert, 2008, p. 35), a sua utilização em concomitância com o ensino pode contribuir para a constituição da cientificidade secretarial e formação de cidadãos, críticos, reflexivos e transformadores da realidade na qual estão inseridos no âmbito social e organizacional. Diversos autores se propuseram abordar a Educação em Secretariado (e.g.: Faria \& Reis, 2008; Silva, Barros \& Sousa, 2010; Dias \& Barros, 2013), porém, a partir de uma busca no portal de periódicos da Coordenação de Aperfeiçoamento de Pessoal de Nível Superior (Capes), não foram encontrados trabalhos nacionais ou internacionais que discutam a temática aqui proposta, nem tampouco a metodologia empregada. Some-se ao exposto, o fato de que a área de Secretariado vivencia um momento de busca e consolidação científica por meio de questionamentos e propostas teóricas.

Diante dessas reflexões e das lacunas apontadas, busca-se responder ao seguinte questionamento: como a metodologia do ensino com pesquisa pode contribuir para a cientificidade na formação secretarial? Este trabalho tem por objetivo geral investigar as contribuições do ensino com pesquisa para a cientificidade secretarial e como objetivos específicos: a) analisar a relevância da pesquisa como estratégia de ensino para a cientificidade da área secretarial por meio da vivência docente; b) conhecer a visão dos discentes acerca da importância do ensino com pesquisa para a cientificidade secretarial. 
A relevância deste trabalho está associada à necessidade de uma formação em Secretariado Executivo por meio da implementação de métodos de ensino e aprendizagem que desenvolvam nos estudantes uma cultura investigativa. Destaca-se, ainda, que a competência para o desenvolvimento de metodologias investigativas de estudantes de Secretariado Executivo pode ser aprimorada no decorrer do curso, por meio do alinhamento entre teorias e pesquisas nas diversas disciplinas e preparar o estudante para a realização da monografia, bem como fortalecer a pesquisa científica na área. Tais experiências podem ser inseridas, também, em outros contextos, como em sua atuação profissional no âmbito das organizações, contribuindo para a execução de suas atividades cotidianas, especialmente, na sistematização e gestão da informação. $\quad$ O presente artigo está dividido em cinco seções, além desta Introdução. A seção dois trata da revisão de literatura centrada no método do ensino com pesquisa. As seções três e quatro abordam, respectivamente, a metodologia da pesquisa e a análise e discussão dos resultados. Por fim, são apresentadas as considerações finais na quinta e última seção seguida das referências que subsidiaram este estudo.

\section{Referencial Teórico: Ensino com Pesquisa como Prática de Ensino na Educação Superior}

A universidade está inserida em um contexto social de profundas e rápidas transformações que a impactam e demandam, principalmente, a ampliação e construção de novos saberes. Nessa linha de pensamento, a instituição universitária tem como finalidade “[...] a liberdade do saber, o alargamento dos horizontes da igualdade de oportunidades, e o aperfeiçoamento da formação humana" (Teixeira, 1969, p. 236). A construção de conhecimentos no universo acadêmico perpassa a concretização da tríade ensino, pesquisa e extensão. A constituição e difusão de saberes deve enfatizar o ensino como meta fundamental, a pesquisa como forma de ampliação e descoberta e a extensão como meio de aplicação dessas inovações (Wanderley, 2003). Sob esse aspecto, Cunha (1996, p. 32) alerta que "a maior parte da comunidade universitária, e em especial os docentes, explicita a ideia de que há indissociabilidade quando o professor faz ensino e tem projetos de pesquisa e extensão".

A concretização dessa tríade não é possível se o ensino, a pesquisa e a extensão forem vistos como aspectos isolados, mas somente será consolidada se forem considerados como funções da universidade que devem ser cumpridas de forma dialógica. Nessa perspectiva, destaca-se a abordagem do ensino com pesquisa como uma prática pedagógica universitária capaz de promover a relação interdisciplinar entre tais funções, visto que a pesquisa pode ser o elo entre a teoria e a aplicação prática, ou seja, o ensino e a extensão. Entretanto, conforme ressalta Cunha (1996, p. 32): 
O desafio da indissociabilidade do ensino com a pesquisa nos cursos de graduação continua presente na universidade. O exercício de pensar e discutir o assunto em diferentes contextos e instituições de ensino superior revela que sequer existe um acordo conceitual sobre o sentido da indissociabilidade e nem uma reflexão sistemática sobre o tema.

Na percepção de Lampert (2008, p. 32):

Na universidade brasileira, quer nos cursos de graduação, quer nos programas de pósgraduação, a pesquisa é praticamente relegada. Há uma preocupação muito acentuada com o formalismo do ensino (normalmente a reprodução de conhecimentos) em detrimento da produção do saber.

Isso significa que assumir a pesquisa como prática de ensino é um desafio para a docência universitária. O ensino com pesquisa emerge como uma estratégia de ensino e representa uma ação pedagógica com foco na investigação participativa de modo que se possa beneficiar a aprendizagem dos alunos.

Na assertiva de Fernandes (2011, p. 80):

Para promover mudanças educacionais, que beneficiem a todos os alunos, o ambiente em que o professor se encontra deve oportunizar momentos de discussão, de questionamentos, de trabalho coletivo e individual, de estudos, enfim, de pesquisa que oportunize efetivamente ao educando o entendimento do que estuda, pois se assim não for permanecerá no senso comum.

Considera-se a sua relevância para a atuação docente, pois "a produção do conhecimento pode ser entendida como a mais importante tarefa e objetivo" da instituição universitária (Mosquera, 2006, p. 85). Além disso, esse método de ensino na educação superior pode ser utilizado como “[...] uma poderosa ferramenta de que se pode lançar mão para introduzir o aluno na iniciação científica, despertando-lhe o gosto pela investigação" (Lampert, 2008, p. 35).

Muitos questionamentos ainda carecem de definição na área educacional acerca do ensino com pesquisa no que se refere à delimitação de conceitos, etapas do seu processo e sua importância para o ensino e a aprendizagem. Neste trabalho, considera-se o conceito de Lampert (2008) ao entender tal método como um conjunto organizado de situações que estimulam e desafiam o processo de aprendizagem, no qual docente e discente atuam como sujeitos ativos. Nessa linha de pensamento, acredita-se que a pesquisa pode contribuir para a formação de profissionais críticos e transformadores da realidade na qual estão inseridos. Em sua ação didática ao decidir pela utilização da pesquisa em sala de aula, o professor universitário, deve compreendê-la como:

[...] um movimento dialético, em espiral, que se inicia com o questionar dos estados do ser, fazer e conhecer dos participantes, construindo-se a partir disso novos argumentos que possibilitam atingir novos patamares desse ser, fazer e conhecer" (Moraes \& Lima, 2002, p. 11). 
Lampert (2008) destaca três etapas do ensino com pesquisa: questionamento: fase inicial da pesquisa que leva os estudantes à existência de dúvidas permanentes em relação aos conhecimentos; argumentação: relação entre teoria e prática para a construção de argumentos que respondam aos questionamentos; comunicação: difusão dos resultados por meio de seminários, artigos, relatórios, apresentações em eventos ou em sala de aula.

Nessa perspectiva, a pesquisa como prática pedagógica na educação superior contribui para a construção de saberes de forma “[...] positiva, pois vai além de um ensino pautado na mera instrução, no mero repasse dos conteúdos escolares que não atendem às necessidades do mundo atual e não contemplam a aprendizagem dos alunos" (Fernandes, 2011, p. 80).

O ensino com pesquisa pode oferecer resultados favoráveis tanto para o estudante, no que se refere à sua aprendizagem, como para o professor como forma de atualização e desenvolvimento intelectual constantes. Sob esse aspecto, Lampet (2008, p. 39), considera:

O ensino com pesquisa não visa a formar um profissional pesquisador, mas incentivar o discente a entender o processo investigativo, ser capaz de usá-lo e conhecer a realidade de forma contextualizada. Por sua vez, para o professor a pesquisa é vista como fonte inesgotável de produção de novos conhecimentos e transformações.

Diante dessas reflexões, entende-se que o ensino com pesquisa requer do docente que atua na educação superior dedicação, rigor científico e disponibilidade para enfrentar desafios, cuja superação pode oferecer resultados eficazes nos processos de ensino e aprendizagem, nos quais o docente passa a atuar como um mediador, estimulador e desafiador em direção à constituição de novos saberes e não apenas como um "transmissor" de informações, mas como um pesquisador em formação contínua. O aprendiz, por sua vez, passa a ser percebido como um sujeito ativo e transformador, capaz de questionar as teorias estudadas em sala de aula.

\section{Metodologia: Os Caminhos da Pesquisa}

Para o alcance dos objetivos propostos, foi desenvolvida uma pesquisa qualitativa ao buscar a compreensão do fenômeno de pesquisa em seu ambiente habitual (Sampieri, Collado \& Lucio, 2006). Foi realizada uma pesquisa participante na qual as pesquisadoras contribuíram para o desenvolvimento da investigação não como coadjuvantes dela, mas a pesquisa se projetou e realizou desdobramentos por meio da participação ativa e crescente de seus atores (professoras, servidora técnico-administrativa e estudantes) (Brandão, 2006).

A pesquisa foi desenvolvida em duas fases. Na primeira fase, desenvolveu-se a técnica de observação participante que compreende “[...] um olhar ativo, sustentado por uma inquietação, uma 
preocupação problemática [...]" (Farias, Silva, Nóbrega-Therrien \& Sales, 2010, p. 70), com o intuito de analisar a relevância da pesquisa como estratégia de ensino para a cientificidade da área secretarial por meio da vivência docente. Por meio da observação participante, registrada em um diário de campo, apresenta-se o relato de experiência docente a partir da descrição do desenvolvimento e dos resultados alcançados com a utilização do ensino com pesquisa científica. Além da observação e do registro das ações realizadas, as investigadoras participaram de forma ativa de todas as etapas e atividades em “[...] diferentes posições na gestão de esferas de poder ao longo do processo de pesquisa assim como na gestão dos processos de ação social dentro da qual a pesquisa participante tende a ser concebida como um instrumento, um método de ação científica" (Brandão, 2006, p. 4, grifos do autor). A investigação foi desenvolvida nas disciplinas Dinâmica Gerencial, Comportamento Organizacional e Estágio Supervisionado, no curso de Secretariado Executivo da Universidade Federal do Ceará (UFC), no período de 2012 a 2014. As ações realizadas com a participação das pesquisadoras envolveram a elaboração do planejamento de pesquisa, orientações em sala de aula, elaboração do instrumento de coleta de dados, análise dos resultados e avaliação.

A aplicação dessa metodologia ocorreu nas citadas disciplinas, contando com a participação de 73 alunos, distribuídos da seguinte forma: 25 alunos que cursaram a disciplina Dinâmica Gerencial em 2012, 23 alunos que cursaram a disciplina Comportamento Organizacional em 2013 e 25 alunos que realizaram Estágio Supervisionado em 2014. Participaram, ainda, duas professoras do curso e uma servidora técnico-administrativa. Dessa forma, a pesquisa teve um total de 76 sujeitos.

A segunda fase investigativa visou conhecer a visão dos discentes acerca da importância do ensino com pesquisa para a cientificidade secretarial. Para tanto, buscaram-se informações acerca das percepções dos discentes em relação à utilização do ensino com pesquisa científica, por meio da técnica de narrativas escritas que segundo Souza (2006, p. 26) constitui-se em “[...] investigação porque se vincula à produção de conhecimentos experienciais dos sujeitos adultos em formação". Ao final da disciplina Estágio Supervisionado foi solicitado aos participantes que discorressem de forma escrita sobre a importância do ensino com pesquisa para a cientificidade secretarial, a partir da experiência desenvolvida na disciplina. Nesta etapa, do total de participantes da investigação 19 estudantes que desenvolveram o Estágio Supervisionado, em 2014, contribuíram com a pesquisa. Com o intuito de manter em sigilo a identidade dos participantes, estes foram denominados pelo termo "Estudante", seguido de um número natural que representa a ordem das narrativas escritas. 
A interpretação das informações foi realizada numa perspectiva hermenêutica fundamentada na compreensão interpretativa fenomenológica, na qual o observador adquire a apreensão de alguma ação social particular (Schwandt, 2006). Em linhas gerais, a hermenêutica pode ser compreendida como filosofia da interpretação.

\section{Análise e Discussão dos Resultados: O Ensino com Pesquisa em Secretariado Executivo}

Nesta seção apresenta-se uma discussão acerca das contribuições da abordagem de ensino com pesquisa para a cientificidade secretarial. Para melhor compreensão divide-se em duas etapas. A primeira apresenta o relato sobre a vivência docente com a utilização dessa estratégia de ensino, a partir dos dados obtidos por meio da observação participante. Na segunda etapa, discute-se a visão dos discentes que participaram das disciplinas com utilização da metodologia do ensino com pesquisa.

\section{A vivência docente do ensino com pesquisa}

Nesta fase da investigação, relata-se a experiência das docentes pesquisadoras acerca do ensino com pesquisa, a partir da observação participante, tendo como foco a investigação científica. Para melhor compreensão sobre a condução docente nas investigações científicas, relata-se como esse método de ensino foi realizado no que se refere à organização dos trabalhos desenvolvidos, às orientações, ao desenvolvimento e às conclusões das pesquisas. A fase inicial ocorreu no planejamento das disciplinas e foram incluídos no plano os objetivos relacionados à pesquisa, a saber: a) contribuir para os processos de ensino e aprendizagem; b) promover o estudo, a convivência e o trabalho em equipe; c) possibilitar pesquisa da prática profissional; d) incentivar a pesquisa científica; e) promover a aplicação dos conceitos estudados em sala de aula para a busca de soluções de problemas relativos à profissão; f) orientar o estudante para a emancipação intelectual.

No planejamento, foi definido que a pesquisa seria o trabalho final das disciplinas. No desenvolvimento das pesquisas nas disciplinas Dinâmica Gerencial e Comportamento Organizacional os temas a serem considerados como objetos de estudos foram delimitados a partir dos assuntos gerais das disciplinas os quais foram relacionados à atuação do secretário executivo. Outro aspecto relevante no planejamento da atividade de pesquisa foi a elaboração de um 
cronograma de atividades a ser seguido no qual foram destacadas a descrição das ações e os prazos a serem cumpridos. Com relação aos aspectos técnicos foi determinado que as pesquisas resultassem em artigos científicos e apresentações orais para a turma. Quanto à avaliação da atividade de pesquisa foram observados os seguintes critérios: a) trabalho escrito: conteúdo, clareza, correção ortográfica, gramatical e normas da Associação Brasileira de Normas Técnicas (ABNT), rigor científico; b) apresentação oral: domínio do conteúdo, qualidade, postura, desenvoltura, criatividade, integração da equipe e recursos utilizados.

Para o desenvolvimento do Estágio Supervisionado com pesquisa, como resultado o estudante sistematizou um documento no formato de um relatório de estágio, conforme orientação docente. No relatório foram incluídos os resultados de uma pesquisa científica desenvolvida a partir de um tema estudado durante as disciplinas do Curso. A avaliação dessa atividade ocorreu por meio do trabalho escrito e considerou os seguintes critérios: a) clareza e correção vernacular dos textos; b) qualidade do conteúdo e da pesquisa de campo; c) avaliação do representante da empresa; d) atendimento às normas da Associação Brasileira de Normas Técnicas (ABNT).

O desenvolvimento das atividades de pesquisa foi realizado no decorrer das disciplinas. As orientações foram feitas a partir de datas predeterminadas no cronograma para entrega das partes do trabalho. Para orientações relativas aos objetivos, problema, instrumentos de pesquisa, levantamento teórico e análise de dados, foram reservados momentos em sala de aula para que os alunos discutissem e trabalhassem em equipe. Os estudantes participaram de todas as fases das investigações e da construção de resultados e reflexões. Finalmente, os estudantes fizeram a entrega do trabalho final em formato de artigo ou relatório que foi corrigido para melhorias. Como resultados do método de ensino com pesquisa nas experiências relatadas destaca-se que essa estratégia ofereceu oportunidade aos estudantes de vivenciarem um processo de aprendizagem centralizado no seu empenho e estudo. Levou-os à reconstrução dos conhecimentos focalizados em disciplinas de áreas afins do Secretariado e contribuiu para a interdisciplinaridade da área. Sobre esse aspecto, Nascimento (2012, p. 109) afirma que:

[...] historicamente, o secretariado é uma área de conhecimento que se vale de estudos teóricos de outras áreas, entre as quais a administração, a psicologia, a economia, a sociologia, a comunicação social e a linguística.

Os resultados da experiência de ensino com pesquisa foram materializados na concretização de artigos científicos e relatórios e envolveu diversos temas de estudos, tais como: motivação, tomada de decisão, trabalho em equipe, liderança, gestão de conflitos, utilização de formas de 
poder, inteligência emocional, funções, habilidades e competências gerenciais, gestão de documentos.

Os temas citados representam os principais assuntos estudados pelos alunos nas disciplinas. Com base nessas temáticas foram delimitados os objetos de estudos das investigações. Após a conclusão das disciplinas, os melhores trabalhos foram indicados para apresentações em eventos acadêmicos. Ressalta-se, ainda, a publicação de trabalhos em periódicos científicos da área secretarial, qualificados pela Capes. O Quadro 1 apresenta uma síntese dos principais trabalhos publicados.

Quadro 1: Síntese dos trabalhos publicados em eventos científicos e periódicos

\begin{tabular}{|c|c|}
\hline Título do trabalho & Publicação \\
\hline $\begin{array}{l}\text { Contribuições da atuação secretarial para a produtividade } \\
\text { nas organizações. }\end{array}$ & Revista Extensão em Ação, vol. 1, n. 8, pp. 56-68, 2015. \\
\hline \multirow{2}{*}{$\begin{array}{l}\text { O papel da inteligência emocional para a atuação do } \\
\text { secretário executivo. }\end{array}$} & Revista Extensão em Ação, vol. 2, pp. 125-139, 2014. \\
\hline & $\begin{array}{l}\text { Artigo premiado nos Encontros Universitários, } 1^{\circ} \text {. lugar no } \\
\text { XXIII Encontro de Extensão - Área: Trabalho, UFC, } 2014 .\end{array}$ \\
\hline \multirow{2}{*}{$\begin{array}{l}\text { Análise das habilidades interpessoais desenvolvidas na } \\
\text { atuação do secretário executivo. }\end{array}$} & Revista Extensão em Ação, vol. 3, pp. 2-13, 2013. \\
\hline & $\begin{array}{l}\text { Artigo premiado nos Encontros Universitários, } 1^{\circ} \text {. lugar no } \\
\text { XXII Encontro de Extensão - Área: Trabalho - Encontros } \\
\text { Universitários, UFC } 2013 \text {. }\end{array}$ \\
\hline $\begin{array}{l}\text { A função gerencial de organização na atuação do secretário } \\
\text { executivo. }\end{array}$ & $\begin{array}{l}\text { I Encontro de Estudos e Pesquisas em Secretariado } \\
\text { Executivo (Enepes), UFC, } 2014 .\end{array}$ \\
\hline $\begin{array}{l}\text { A relevância dos traços de personalidade e valores para a } \\
\text { atuação do profissional de Secretariado Executivo. }\end{array}$ & tários, UFC, 2014. \\
\hline $\begin{array}{l}\text { Estilos de liderança em instituição pública: percepção dos } \\
\text { estagiários em Secretariado Executivo. }\end{array}$ & Encontros Universitários, UFC, 2014. \\
\hline $\begin{array}{l}\text { O papel gerencial de produtor: contribuições da atuação } \\
\text { secretarial para a produtividade nas organizações. }\end{array}$ & Encontros Universitários, UFC, 2014. \\
\hline $\begin{array}{l}\text { O secretário executivo e } \\
\text { organizações. }\end{array}$ & $\begin{array}{l}\text { I Encontro de Estudos e Pesquisas em Secretariado } \\
\text { Executivo (Enepes), UFC, } 2014 .\end{array}$ \\
\hline \multirow[t]{2}{*}{$\begin{array}{l}\text { As atividades e competências necessárias à gestão } \\
\text { secretarial nas organizações contemporâneas. }\end{array}$} & $\begin{array}{l}\text { XII Seminário Multiprofissional Integrado de Secretariado } \\
\text { (Semsec), } 2013 .\end{array}$ \\
\hline & $\begin{array}{l}\text { Artigo premiado em } 1^{\circ} \text {. lugar na categoria pôster no XII } \\
\text { Seminário Multiprofissional Integrado de Secretariado } \\
\text { (Semsec), } 2013 \text {. }\end{array}$ \\
\hline $\begin{array}{l}\text { Inteligência Emocional no trabalho: estudo na Universidade } \\
\text { Federal do Ceará. }\end{array}$ & Encontros Universitários, UFC, 2012. \\
\hline
\end{tabular}

Fonte: Elaborado pelas autoras.

Considera-se que o ensino com pesquisa como prática na formação em Secretariado Executivo contribuiu para que os alunos divulgassem os conhecimentos construídos nas disciplinas 
estudadas para a comunidade acadêmica e para a sociedade, além de colaborar para a cientificidade da área. A experiência relatada neste trabalho remete a algumas reflexões acerca da contribuição da abordagem do ensino com pesquisa para os processos de ensino e aprendizagem, visto que possibilitou a concretização do processo cognitivo e levou os estudantes à construção de significados acerca da práxis secretarial. Nessa direção Gomes, Figueiredo e Ghedin (2011, p. 10) afirmam:

O ensino com pesquisa é capaz de mobilizar vários processos cognitivos, isto porque falar de processos cognitivos implica a compreensão sobre nossa capacidade de pensar, aprender e construir significados, de perceber o mundo que nos rodeia.

Essa estratégia possibilitou, também, uma integração entre docentes e discentes por meio das responsabilidades compartilhadas nos estudos realizados, visto que o ensino com pesquisa “considera o aluno e o professor como pesquisadores e produtores dos seus próprios conhecimentos" (Behrens, 2005, p. 56).

Observa-se que o desenvolvimento da pesquisa científica possibilitou um diálogo entre os aspectos teóricos abordados nas disciplinas e a prática secretarial, sendo uma forma de ultrapassar os muros da universidade e conhecer a percepção dos profissionais que atuam na área acerca dos temas propostos. Na visão de Gomes, Figueiredo e Ghendi (2011, p. 10):

Somos capazes de apreender o mundo por meio de nossos processos cognitivos, pois o ser humano é o único que interpreta a realidade de acordo como a percebe, modificando-a, transformando-a na medida em que se modifica também.

Como o curso de Secretariado Executivo da UFC, atualmente, é essencialmente teórico, esse método de ensino pode representar uma oportunidade para que o discente analise de forma crítica e reflexiva a práxis da profissão e apreenda os significados da realidade desse profissional, pois "nem só de prática subsiste um curso e o conhecimento humano, há de se compor e complementar o valor dos conhecimentos, como componentes intelectuais necessários à construção do mundo" (Hoeller, 2006, p. 145).

Outro aspecto que merece atenção é o fato de que essa metodologia de ensino levou os estudantes à elaboração de novos conhecimentos por meio do levantamento bibliográfico, a partir da busca por diversos autores que abordassem o seu tema de investigação, evitando a limitação dos conteúdos aos textos selecionados para as disciplinas. Nesse sentido, o estudante:

[...] deixa de ser passivo no processo da aprendizagem e constitui-se como um ser ativo capaz de dialogar com a realidade, problematizando-a, questionando-a, levantando 
hipótese e buscando novas formas de construí-la o que lhe permite atribuir novos significados a ela (Gomes, Figueiredo \& Ghedin, 2011, P.10).

No decorrer das atividades observou-se a existência de alguns desafios para a concretização das atividades de pesquisa. Dentre as limitações para o trabalho com os estudantes, ressalta-se a ausência de uma cultura de ensino por meio da pesquisa no curso investigado. Nessa realidade, buscou-se auxiliá-los nas diversas etapas da investigação, nas reuniões em sala de aula e por meio de correções feitas nos capítulos elaborados.

A análise ora realizada leva à percepção das dificuldades enfrentadas pelos estudantes e pelos docentes na condução da pesquisa como uma estratégia de ensino superior, visto que ao conceber esse método como elemento indispensável em suas aulas, o professor deve compreender que o processo de ensino não envolve somente:

[...] domínio de uma área específica do conhecimento, mas conhecer a respeito da cognição humana, pois saberá como o estudante aprende e como este dar significados àquilo que aprende, sendo capaz não apenas de memorizar, mas também de construir seus conhecimentos por meio de uma didática que lhe permita isso (Gomes, Figueiredo \& Ghedin, 2011, p.10).

No âmbito do Secretariado concorda-se com os autores citados, visto que as práticas de ensino na área devem criar espaços de construção e reconstrução de conhecimentos. Considera-se que os docentes devem vincular suas atividades de ensino ao desenvolvimento da pesquisa científica. A seguir, analisa-se a percepção dos discentes em relação à temática proposta.

\section{O ensino com pesquisa em Secretariado Executivo: visão de discentes}

Nesta etapa da investigação são apresentadas as informações coletadas por meio das narrativas escritas de estudantes que desenvolveram Estágio Supervisionado com a metodologia de pesquisa. Objetivou-se conhecer a visão dos discentes acerca da importância do ensino com pesquisa para a cientificidade secretarial. Acerca da importância da pesquisa em seu processo formativo, o Estudante 1 considera que isso se deve ao fato de oportunizar um diálogo entre a teoria e a realidade da prática secretarial. Para o Estudante 3 a pesquisa é enriquecedora ao possibilitar “[...] o aprofundamento sobre um tema específico e o conhecimento de pontos de vista similares e diferentes". Nesse sentido, a relevância da pesquisa para o Secretariado como área de conhecimento científico, destaca-se pelo fato de proporcionar o desenvolvimento de debates e confrontos de ideias o que leva à constituição de novos conceitos. Na compreensão do Estudante 4 "a inclusão da pesquisa no relatório final estimula o desenvolvimento do senso crítico do estudante e a forma de 
perceber onde ele está inserido [...]". Com relação a essa contribuição, ponderou-se que a cientificidade secretarial é contemplada por meio do ensino com pesquisa por abrir "um leque de conhecimentos" (Estudante 19). Essas percepções confirmam o que defendem Gomes, Figueiredo e Ghedin (2011) ao refletirem que o ensino com pesquisa mobiliza o desenvolvimento de processos cognitivos e tem como consequência a compreensão da capacidade de pensar, aprender e elaborar significados no contexto no qual os sujeitos estão inseridos. Assim, o estudante é preparado para intervir na realidade na qual atua.

Percebeu-se que os estudantes se sentem impulsionados a enfrentar novos desafios e modos de aprender, ao serem direcionados à pesquisa, conforme afirmação do Estudante 18 ao ponderar que os alunos se sentem motivados quando são exigidos, chamados à participação com mais empenho e se deparam com trabalhos bem elaborados ao final do semestre. Essa percepção denota que a inclusão da pesquisa nos processos de ensino e de aprendizagem vai além da transmissão de conteúdos superando a prática de ensino pautada na instrução a qual não atende às necessidades da realidade contemporânea (Fernandes, 2011). Dessa forma, o ensino com pesquisa leva o estudante a ser o principal agente da sua aprendizagem, pela possibilidade de transformar as informações obtidas por meio da investigação científica em novos conhecimentos.

O Estudante 5 afirmou que o ensino com pesquisa "[...] contribui para lançar um olhar sobre a prática profissional orientada, sobretudo, pelas teorias". Essa visão é complementada por outro estudante ao destacar que "[...] contribui para a cientificidade do Secretariado e principalmente, de profissionais pesquisadores" (Estudante 4). Sobre esse aspecto, compreende-se que o ensino com pesquisa incentiva o estudante a utilizar o processo investigativo e o capacita para utilizá-lo e compreender a realidade na qual está inserido de forma contextualizada (Lampert, 2008). Isso pode significar um avanço científico na área de Secretariado por formar profissionais aptos a ultrapassarem a visão tecnicista da profissão e a atuarem de forma crítica, capazes de refletirem acerca do fazer secretarial, bem como relacionarem suas atribuições à busca de soluções aos problemas que emergem em seu cotidiano com um olhar teórico. Foi abordado, ainda, que a pesquisa proporciona a formação de pesquisadores, como se observa da afirmação a seguir: "Na minha avaliação [...] a pesquisa científica é válida; propicia ao aluno exercitar seu lado pesquisador e abrir novos horizontes, despertando o gosto pela pesquisa em si" (Estudante 11). Nessa linha de pensamento, destaca-se a seguinte opinião: “[...] o gosto pela pesquisa aumenta quando somos postos à prova dessa maneira" (Estudante 18). No entendimento do Estudante 13 "na esfera acadêmica as contribuições foram no sentido de melhorar a produção dos textos acadêmicos". 
Reflete-se que a associação do ensino à pesquisa científica em Secretariado pode ser um importante instrumento para a introdução do acadêmico na iniciação científica e o despertar para o gosto pela investigação (Lampert, 2008). Observa-se que os participantes desta investigação, consideram que uma importante contribuição do ensino com pesquisa para a cientificidade secretarial é a inserção do aluno no ambiente investigativo por meio do aprimoramento de metodologias de pesquisa científica, do exercício da produção textual acadêmica e da motivação do formando para o desenvolvimento de pesquisas.

Considera-se que "a pesquisa está ou deveria estar em todas as universidades que aspiram a oferecer melhores condições de vida à sociedade, pois ela abre novas possibilidades, novos horizontes, novas descobertas e novos caminhos, além de propiciar um ensino com qualidade" (Lampert, 2008, p. 33). Assim, a abordagem do ensino com pesquisa pode ser um meio para que a atuação docente na educação superior contribua para a consolidação do Secretariado como ciência.

\section{Considerações Finais}

A realização deste trabalho possibilitou algumas considerações acerca das contribuições do ensino com pesquisa para a cientificidade secretarial e estabeleceu uma discussão sobre a relevância da pesquisa como estratégia de ensino para a área. A pesquisa revelou que essa abordagem impõe diversos desafios à docência universitária a fim de que se possa orientar os aprendizes no caminho da cientificidade e implementar na área secretarial uma cultura de desenvolvimento científico, de divulgação dos conhecimentos gerados no âmbito acadêmico e, assim, se possa colaborar para a consolidação do Secretariado no meio acadêmico. Observou-se que, na visão dos discentes, a estratégia de ensino com pesquisa é importante para a cientificidade secretarial por possibilitar ao educando o aprimoramento de práticas metodológicas de pesquisa, o exercício de produção textual acadêmica, a motivação e o gosto pela pesquisa. Além disso, a vivência dos participantes apontou que esse método os leva à emancipação intelectual ao tornar os estudantes em sujeitos ativos na produção de conhecimentos. Outro aspecto elucidado é o fato de se promover um ambiente educativo capaz de levar o aluno ao pensamento reflexivo e formar profissionais aptos a superarem a visão tecnicista da profissão por meio do pensamento crítico acerca do fazer secretarial, por meio do alinhamento de teoria e prática.

Quanto à questão norteadora, considera-se que a metodologia de ensino com pesquisa pode contribuir para a cientificidade na formação secretarial por meio da inovação metodológica, ao 
inserir nos processos de ensino e aprendizagem uma ação pedagógica que ultrapassa a mera transmissão de informações. O educando surge como o principal agente desses processos, ao buscar respostas para as questões empíricas e teóricas que desafiam o cotidiano acadêmico e profissional do Secretariado.

Entende-se que o formando em Secretariado Executivo deve ser capaz de intervir de forma crítica e reflexiva ao ingressar no mundo do trabalho de modo que ultrapasse as barreiras do "saberfazer" por meio do exercício constante da práxis ao concretizar a relação teoria-prática. Pondera-se que a sua formação não pode ser fundamentada somente em práticas de ensino limitadas à ação didática em sala de aula. Nessa linha de raciocínio, a pesquisa emerge como um novo desafio para a educação em Secretariado, por ser um dos principais caminhos as serem seguidos na construção de novos conhecimentos. Infere-se, portanto, que as contribuições do ensino com pesquisa para a cientificidade secretarial ocorrem, principalmente pelo fato de formar um novo perfil acadêmico e profissional por meio de uma cultura científica no curso e insere o aluno no processo investigativo durante a realização das disciplinas estudadas ao longo de sua trajetória universitária. Tal cultura possibilita a busca por respostas às inquietações que surgem na profissão e colabora para a identidade do Secretariado como área de conhecimento científico em construção. Considera-se a importância do tema e ressalta-se a necessidade de estudos que ampliem e aprofundem aspectos teóricos e empíricos relacionados à abordagem de ensino com pesquisa em Secretariado Executivo. Sugere-se o desenvolvimento de investigações acerca da relação entre ensino e pesquisa, tais como: aprendizagem por meio do ensino com pesquisa, ensino com pesquisa no estágio supervisionado, ensino com pesquisa na prática docente.

\section{Referências}

Behrens, Marilda Aparecida (2005). O paradigma emergente e a prática pedagógica. Petrópolis: Vozes.

Bíscoli, Fabiana Regina Veloso \& Bilert, Vania Silva de Souza (2013). Evolução do secretariado executivo: caminhos prováveis a partir dos avanços da pesquisa científica e dos embates teóricos e conceituais na área. Revista Expectativa. vol. 12, n. 12, pp. 9-42.

Brandão, Carlos Rodrigues (2006). A pesquisa participante e a participação na pesquisa: um olhar entre tempos e espaços a partir da América Latina. In: Brandão, Carlos Rodrigues \& Streck, Danilo Romeu (Org). Pesquisa participante: o saber da partilha (2a ed.) Aparecida, São Paulo: Ideias et Letras. 
Cunha, Maria Isabel da (1996.). Ensino com pesquisa: a prática do professor universitário. Cad. Pesq., São Paulo, n. 97, pp. 31-46.

Dias, Ana Maria Iorio \& Barros, Conceição de Maria Pinheiro (2013). Reflexões sobre a prática e a formação do secretário(a) executivo(a) na docência universitária. In: Santos, Alice Nayara \& Rogério, Pedro (Org.). Currículo: diálogos possíveis. Fortaleza: Edições UFC.

Faria. D. S. \& Reis, A. C. G. (2008). Docência em Secretariado Executivo. Fazu em Revista, Uberaba, n. 5, 2008, pp. 169-174.

Farias, Isabel Maria Sabino de.; Silva, Silvina Pimentel; Nóbrega-Therrien, Silvia Maria \& Sales, José Albio Moreira de Sales (2010). Trilhas do labirinto na pesquisa educacional qualitativa: dos procedimentos de coleta de dados ao trabalho de campo. In: Farias, Isabel Maria Sabino de; Nunes, João Batista Carvalho \& Nóbrega-Therrien, Silvia Maria. Pesquisa científica para iniciantes: caminhando no labirinto. Fortaleza: Eduece, pp. 67-92.

Fernandes, Christiane Caetano Martins (2011). A pesquisa em sala de aula como instrumento pedagógico: considerações para sua inclusão na prática pedagógica. Diálogos Educ. R., Campo Grande, MS, vol. 2, n. 2, pp. 74-82.

Gomes, Ruth Cristina Soares; Figueiredo, Ângela Maria Rodrigues de \& Ghendin, Evandro (2011). Os processos cognitivos mobilizados pelo ensino com pesquisa na pedagogia universitária. Rev. Areté, vol. 4, n. 6, Manaus, pp. 9-13.

Hoeller, Patricia Agostinho Freitas (2006). A natureza do conhecimento em Secretariado Executivo. Revista Expectativa, vol.5, n. 5, pp. 139-145.

Lampert, Ernâni (2008). O ensino com pesquisa: realidade, desafios e perspectivas na universidade brasileira. Revista Galego-portuguesa de Psicoloxíae Educación. Vol. 16, (1,2), Ano $12^{\circ}$, pp. 31-44.

Moraes, Roque de. \& Lima, Valderez Marina do Rosário (2002). Pesquisa em sala de aula: tendências para a educação em novos tempos. Porto Alegre: Edipucrs.

Mosquera, Juan Jose Moriño (2006). Princípios da universidade no século XXI: universidade e produção do conhecimento. In: Audy, Jorge Luis Nicolas \& Morosini, Marília Costa (Orgs.). Inovação e empreendedorismo na universidade. Porto Alegre: Edipucrs, pp. 70-88.

Nascimento, Erivaldo Pereira do (2012). Pesquisa aplicada e interdisciplinaridade: da linguística ao secretariado. In: Durante, Daniela Giareta (Org). A pesquisa em secretariado: cenário, perspectivas e desafios. Passo Fundo: Ed. Universidade de Passo Fundo.

Nonato Júnior, Raimundo (2009). Epistemologia e teoria do conhecimento em secretariado executivo: a fundação das ciências da assessoria. Fortaleza: Expressão Gráfica.

Sabino, Rosimeri Ferraz \& Marchelli, Paulo Sérgio Marchelli (2009). O debate teóricometodológico no campo do secretariado: pluralismos e singularidades. Cadernos EBAPE.BR, n. 4, art. 6, pp. 607-621. 
Sampieri, Roberto Hernández; Collado, Carlos Fernández \& Lucio, Pilar Baptista (2006). Metodologia de pesquisa (3a. ed.) São Paulo: McGraw-Hill.

Silva, Joelma Soares da; Barros, Conceição de Maria Pinheiro \& Sousa, Elaine Freitas de (2010). Docência em Secretariado Executivo: a valoração da experiência extraclasse. Revista Expectativa, vol. 9, nº 1, pp. 43-60.

Souza, Elizeu Clementino de (Org.) (2006). Autobiografias, história de vida e formação: pesquisa e ensino. Salvador/Bahia: Eduneb - Edipucrs.

Schwandt, Thomas A (2006). Três posturas epistemológicas para investigação qualitativa: interpretativismo, hermenêutica e construtivismo social. In: Denzin, Norman K. \& Lincoln, Yvonna S. O planejamento da pesquisa qualitativa: teorias e abordagens. Porto Alegre: Artmed, pp. 193297.

Teixeira, Anísio (1969). Educação e o mundo moderno. São Paulo: Editora Nacional

Wanderley, Luiz Eduardo (2003). O que é universidade. São Paulo: Brasiliense. 